\title{
Saliva from Patients with Cystic Fibrosis Inhibits Amiloride-Sensitive Sodium Transport
}

\author{
PETER C. WILL, ANNE TAYLOR, JONATHAN L. LEBOWITZ, DORR G. DEARBORN, AND \\ ULRICH HOPFER' \\ Departments of Anatom! and Pediatrics, School of Medicine and Developmental Biologi Center. Case Western \\ Reserve University, Cleveland. Ohio, USA
}

\begin{abstract}
Summary
A factor is present in the saliva and sweat from patients with cystic fibrosis (CF) which inhibits the reabsorption of sodium in the ducts of the salivary and sweat glands. Inasmuch as the physiology of sodium absorption is similar in salivary ducts and the distal colon, we have examined the sensitivity of the sodium absorption in the rat colon to saliva from CF patients.

Sodium absorption by the rat colon, estimated as the shortcircuit current, was inhibited by saliva from both patients with $\mathrm{CF}$ and normal volunteers. However, only with $\mathrm{CF}$ saliva was the inhibition consistently proportional to the saliva concentration. Furthermore, the inhibitory activity of $\mathrm{CF}$ saliva was greater than the inhibition observed with saliva from age- and sex-matched controls (percentage of inhibition: $\mathrm{CF}=20.1 \pm 2.2$, and controls $=14.9 \pm 2.1 ; P<0.02$ ), and the inhibition of the colonic shortcircuit current was proportional to the activity measured by the ductal retrograde perfusion assay with the rat parotid gland (linear correlation coefficient $=0.634 ; P<0.005$ ). This latter assay is an accepted assay for $\mathrm{CF}$ factor activity.

We conclude that the $\mathrm{CF}$ factor present in saliva probably interacts in a reversible manner with the amiloride-sensitive sodium transport system which is present in all sodium scavenging epithelia. The rat colon is a promising assay system for $\mathrm{CF}$ factor activity because the electrical measurements permit a rapid quantitative estimate of activity and a single piece of tissue can be used to measure the activity of several saliva samples.
\end{abstract}

\section{Speculation}

The factor that inhibits sodium reabsorption in the ducts of the sweat and salivary glands may be a normally occurring substance which, however, is secreted at abnormal levels in the sweat and saliva in cystic fibrosis.

Saliva and sweat from patients with cystic fibrosis (CF) contain a factor which inhibits the reabsorption of sodium in the ducts of the exocrine glands $(10,11,24,27,28,38)$. This factor has not been purified and identified principally because of its lability and the difficulty of the ductal retrograde perfusion assay (38). Although a number of other assays for CF inhibitor activity have been proposed $(1,5,30)$ each of these has been found by subsequent examination either to lack specificity for CF or to be unrelated to the impairment of electrolyte transport $(2,3,37)$. Tissues responsive to CF inhibitor activity, such as the ducts of the salivary and sweat glands, are low conductance or "tight" epithelia (16. 19). These and other low conductance epithelial tissues, including the distal renal tubule. the collecting tubule, and the colon, share the characteristics of sodium chloride absorption against high concentration gradients, the ability to generate relatively high transepithelial potentials (35), regulation by aldosterone (21), and sensitivity of the sodium transport to the diuretic amiloride $(29,34)$. CF inhibitor activity is effective on the luminal surface of the sweat and saliva duct and is apparently not effective at inhibiting sodium or sodium-dependent nonelectrolyte transport by the brush border membrane of the small intestine $(37,39)$. Therefore, we have suggested that this CF factor may interact specifically with the amiloride-sensitive sodium transport which is unique to low conductance epithelia $(32,39)$.

To test our hypothesis of an interaction of the CF factor with the amiloride-sensitive sodium transport system, the colon from sodium-deficient rats was chosen as a tissue with this type of sodium absorption. The CF specificity was examined in two ways: by comparing the inhibition observed in mixed submaxillarysublingual saliva from $C F$ patients to that of saliva from age- and sex-paired controls and by comparing the inhibition observed with the colonic assay to that observed with the ductal retrograde perfusion assay (38). This latter assay is an accepted estimate of CF factor activity because it correlates with the sweat electrolye test used to diagnose $\mathrm{CF}(10,20,27,38)$.

\section{MATERIALS AND METHODS}

PATIENTS AND CONTROL SUBJECTS

Patients contributing saliva for this study were from the Cleveland Cystic Fibrosis Center. Their clinical scores ranged from 23 to 74 as determined by a modified procedure (12) of the original Shwachman-Kulczycki method (36). Control donors were student volunteers or young laboratory personnel. $\mathrm{CF}$ patients and control donors were matched for sex and age as nearly as possible; the pairing was maintained whenever repeated measurements of activity were done on the same patient. Informed consent was obtained from patients and volunteers contributing saliva.

\section{SALIVA COLLECTION}

Mixed submaxillary-sublingual saliva was collected with Schneyer-type segregators $(33,38)$ between 0830 and 1130 using lemon juice stimulation. The saliva was kept at $\sim 4^{\circ} \mathrm{C}$ and was assayed for activity within $6 \mathrm{hr}$ of collection. Because CF factor activity has been reported to be sensitive to contact with glass ( 27 $28)$ the assay chambers were made of plastic and saliva was handled with plastic vesseis and pipets.

\section{ANIMAL.S}

Male Sprague-Dawley rats of 100 to $500 \mathrm{~g}$ were maintained at $18-24^{\circ} \mathrm{C}$ in a room with a $12 \mathrm{hr}$ light/dark cycle. Animals were housed in plastic cages with aspen straw bedding and were given food and deionized water ad libitum. The control diet was Formulab Chow 5008 supplied by the Ralston Purina Co., Richmond. IL. The sodium-deficient diet was similar to that of Hartroft and Eisenstein (22) and was prepared by the Life Science Group of ICN Pharmaceuticals Inc., Cleveland, OH (catalogue no. 902902). Diets were purchased in pellet form at $\sim 4$-month intervals and were stored at $\sim 4^{\circ} \mathrm{C}$. 
Although rats on the sodium-deficient diet grew more slowly than rats on the normal diet, they remained healthy and achieved a normal adult weight. Before surgical procedures animals were anesthetized with sodium pentobarbital (60 to $90 \mathrm{mg} / \mathrm{kg}$ ) IP.

For the colonic assay, the rats were obtained from Zivic-Miller Laboratories Inc., Allison Park. PA [strain no. $\mathrm{Zml}: \mathrm{AM}(\mathrm{SD}) \mathrm{BR}$ ]. For the ductal retrograde perfusion assay (38), the rats were obtained from ARS Sprague-Dawley, Madison. WI (strain Spd).

\section{MEASUREMENT OF INHIBITORY ACTIVITY}

The descending colon was removed. rinsed with oxygenated Krebs-Henseleit balanced salt solution (26) at $37^{\circ} \mathrm{C}$, and mounted in either a $0.69 \mathrm{~cm}^{2}$ Ussing chamber (42) or a $0.28 \mathrm{~cm}^{2}$ Schultz chamber (31). The tissue was bathed at $37^{\circ} \mathrm{C}$ with a KrebsHenseleit solution containing $5 \mathrm{mM}$ D-glucose and was gassed with $5 \%$ carbon dioxide and $95 \%$ " oxygen. The short-circuit current was measured using a conventional circuit (42) with calomel electrodes as the current electrodes and either calomel or silver/ silver chloride electrodes with $3 \mathrm{M}$ potassium chloride/2\% agar bridges for the potential electrodes. Tissue resistance was calculated from the potential change caused by introducing $\sim 50 \mu \mathrm{A}$ across the tissue. Saliva was preincubated to $37^{\circ} \mathrm{C}$ for $10 \mathrm{~min}$ before adding to the mucosal solution. Inhibition is expressed as the percentage of change in the short-circuit current following addition of saliva (see text). In some cases, artificial saliva was used to mimic the electrolyte composition of submaxillary-sublingual saliva (8): $13 \mathrm{mM}$ sodium chloride. $3.5 \mathrm{mM}$ sodium dihydrogen phosphate. $3.5 \mathrm{mM}$ sodium bicarbonate. $16.2 \mathrm{mM}$ potassium bicarbonate. $1.5 \mathrm{mM}$ calcium chloride. and $1.1 \mathrm{mM}$ magnesium chloride adjusted to $\mathrm{pH}$ 7.0.

The ductal retrograde perfusion assay with the rat parotid gland was performed according to Taylor $e t$ al. (38). The rats were given injections SC with $0.15 \mathrm{M}$ sodium chloride ( $2 \%$ body weight) 0.5 to $2 \mathrm{hr}$ before anesthesia to ensure proper hydration.

\section{STATISTIC AL ANALYSIS}

Statistical comparison of paired samples was done by Student's $t$ test where the distribution of the test statistic was assumed to be normally distributed (7). The mean difference for each individual pair was used to estimate the significance of paired differences for the sample population. The CF sample population is believed to represent the CF population because the range of the clinical scores of the sample population is similar to the range of the clinical scores of the CF patients of the same age group (15 to 31 years) in the Cleveland Cystic Fibrosis Center. For testing the significance of the correlation between the inhibitory activities measured by the two assays, it was assumed that the population correlation coefficient was zero (7).

\section{RESULTS}

Results with normal rat colon indicate that the short-circuit current is insensitive to either CF saliva or amiloride (see Fig. Ib). However, a report by Edmonds and Pilcher (15) demonstrated that placing rats on a sodium-deficient diet stimulates electrogenic sodium absorption. Subsequently, we found that the colon from sodium-deficient rats is sensitive to amiloride $\left(\geq 90^{\prime \prime}\right)$ and to $\mathrm{CF}$ saliva (see Fig. Ia). The short-circuit current is due to electrogenic sodium transport for the following reasons: (1) substitution of the sodium chloride and the sodium bicarbonate in the Krebs-Henseleit balanced salt solution with choline chloride and choline bicarbonate greatly reduces the short-circuit current (from 252 to $15 \mu \mathrm{A} / \mathrm{cm}^{2}$ ) and the potential (from 11.8 to $0.8 \mathrm{mV}$ : the residual is probably due to sodium from the tissue and from the asymmetry potential). Similar results have been reported by Edmonds and Marriott (14). When the sodium concentration in the luminal compartment was varied over the range from 2 to $140 \mathrm{mM}$ sodium. the short-circuit current increased in a hyperbolic manner until at a constant level at $\geq 100 \mathrm{mM}$ sodium (Fig. 2): (2) the colonic

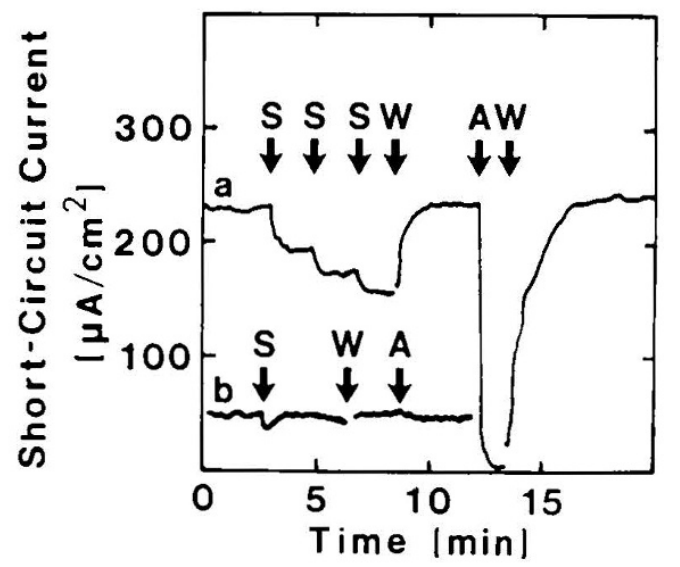

Fig. I. Effect of $\mathrm{CF}$ saliva and amiloride on the short-circuit current of the rat colon. Short-circuit current of the descending colon from sodiumdeticient $(a)$ and normal $(b)$ rats was measured as described in "Materials and Methods." At the additions marked " $S$ " and " $A$, " $C F$ saliva or amiloride were added to the mucosal solution to final concentrations of 25 (v/v), 40, 50"i and $50 \mu \mathrm{M}$, respectively. Saliva and amiloride were washed out " $W$ " by replacing the mucosal solutions with fresh buffer

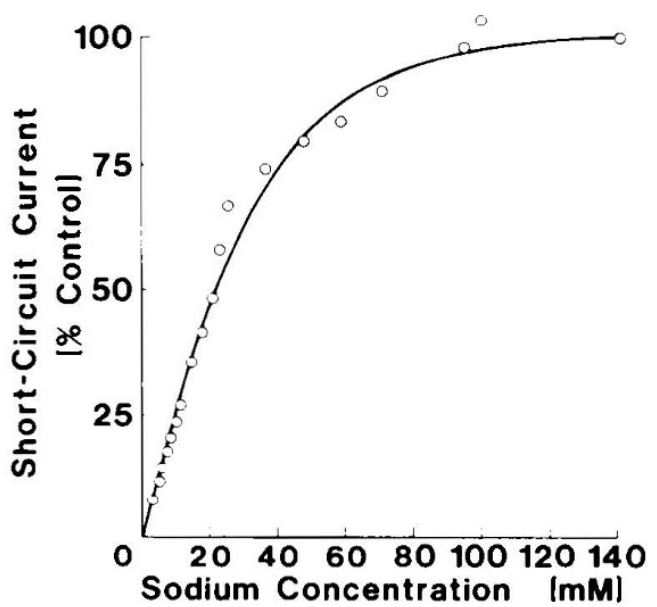

Fig. 2. Sodium dependence of the short-circuit current of the colon from sodium-deficient rats. The short-circuit current was measured as described in "Materials and Methods." The Krebs-Henseleit solution in the mucosal compartment which contained $120 \mathrm{mM}$ sodium chloride. 25 $\mathrm{mM}$ sodium bicarbonate, $4.6 \mathrm{mM}$ potassium chloride. $1.2 \mathrm{mM}$ potassium phosphate. $1.2 \mathrm{mM}$ magnesium sulfate, and $1.0 \mathrm{mM}$ calcium chloride was replaced with a solution in which choline salts replaced those of sodium. At 1- to 2-min intervals, the sodium-containing Krebs-Henseleit solution was added to gradually increase the mucosal sodium concentration. Sodium concentrations were verified by analysis with a sodium-specific electrode (Orion model 94-11). The short-circuit current is shown as a percentage of that observed in the presence of the sodium containing Krebs-Henseleit solution $\left(252 \mu \mathrm{A} / \mathrm{cm}^{2}\right)$. Similar results were obtained when the sodium-containing Krebs-Henseleit solution was gradually diluted with the choline containing solution. In both experiments, the serosal compartment contained the sodium-rich Krebs-Henseleit solution (26).

epithelium from sodium-deficient rats is capable of reducing the luminal sodium concentration from $111 \mathrm{mM}$ in the cecum to 3 $\mathrm{mM}$ in the stool (13); and (3) $3.6 \mathrm{mM}$ furosemide. $1 \mathrm{mM}$ acetazolamide, and $1 \mathrm{mM} 4$-acetamido-4'-isothiocyano-2,2'-disulfonic stilbene, which are known inhibitors of anion transport $(4,6,25)$, do not inhibit the short-circuit current of the descending colon from sodium-deficient rats. These results argue that the shortcircuit current of the colon from sodium-deficient rats is due to a net mucosal to serosal sodium transport which is involved in 
sodium absorption. The short-circuit current of the normal rabbit colon, which is amiloride sensitive (18), has been shown to be an accurate measure of net sodium absorption (17) and is inhibited by CF saliva (results not shown). Therefore, it is likely that sodium absorption via the amiloride-sensitive pathway is inhibited by some substance in saliva.

When the colon from a sodium-deficient rat is treated with amiloride on the luminal surface, the tissue resistance is increased (Table 1). Evidently, the amiloride-sensitive sodium conductance constitutes a measurable fraction of the total tissue conductance. If saliva interacts with the amiloride-sensitive sodium transport system, then saliva should also increase the tissue resistance. The results in Table $I$ indicate that both control and CF saliva significantly increase the tissue resistance. consistent with an interaction of a saliva component with the amiloride-sensitive sodium transport system.

By replacing the mucosal solution with fresh buffer without amiloride or CF saliva, the short-circuit current returns to the pretreatment value (Fig. $l a$ ). Inasmuch as the effects of both saliva and amiloride can be reversed by washing the tissue and because the tissue resistance returns to pretreatment values (results not shown), these agents probably do not act by affecting the integrity or viability of the tissue.

The ability of the short-circuit current assay to detect CF-related inhibitory activity was examined in two ways. First, the inhibition by control saliva was compared to that by CF saliva. Because the inhibition by control saliva is relatively independent of concentration (Fig. 3), the inhibition by saliva may be expressed as the specific inhibition (the inhibition by $50 \%$ saliva minus the inhibition by $25 \%$ saliva). The specific inhibition by CF saliva is significantly greater than that by control saliva (Table $1, P<$ 0.02 ), indicating that the short-circuit current assay is measuring an activity which is elevated in CF.

The relevancy of the inhibition measured by the colonic shortcircuit current assay to CF was also tested by comparing the inhibition of the short-circuit current to the inhibition observed with the ductal retrograde perfusion assay (38). The data (Fig. 4) although variable. demonstrate a significant correlation (with 31 pairs, the linear correlation coefficient was 0.634 at $P<0.005$ ). We conclude from these results that the short-circuit current assay measures as activity which is elevated in CF and is probably attributable to the CF factor.

Because saliva has a much lower sodium concentration than $\mathrm{K}$ rebs-Henseleit balanced salt solution $(8,26,41)$. It would be

Table 1. Tissue resistance and inhibition of colonic short-circuit current after treatment with amiloride and saliva'

\begin{tabular}{|c|c|c|c|}
\hline Additions & $\begin{array}{l}\text { Tissue resistance } \\
\qquad\left(\Omega \mathrm{cm}^{2}\right)\end{array}$ & $\begin{array}{l}\text { Absolute inhibition } \\
\text { (c) }\end{array}$ & $\begin{array}{l}\text { Specilic inhibi- } \\
\text { (ion } \\
\text { (ci) }\end{array}$ \\
\hline one & $59.1 \pm 5.7^{2}(13)^{3}$ & & \\
\hline $\begin{array}{l}0 \underset{\mu \mathrm{M}}{0} \text { ami- } \\
\text { loride }\end{array}$ & $95.0 \pm 7.7 \quad(13)^{\prime}$ & $91.3 \pm 2.2(13)^{1}$ & \\
\hline None & $62.4 \pm 4.7 \quad(23)^{\prime}$ & & \\
\hline $\begin{array}{l}\text { Control } \\
\text { liva }\end{array}$ & $78.7 \pm 6.1 \quad(14)^{\prime}$ & $14.9 \pm 2.1(15)$ & $13.0 \pm 3.2(15)$ \\
\hline CF Saliva & $77.1 \pm 7.5 \quad(11)^{1}$ & $20.1 \pm 2.2(15)^{1}$ & $16.0 \pm 3.2(15)^{\circ}$ \\
\hline \multicolumn{4}{|c|}{$\begin{array}{l}\text { 'The resistance was measured before and after treatment with } 50 \mu \mathrm{M} \\
\text { amiloride or } 50 \% \text {; saliva. The absolute inhibition was that observed in the } \\
\text { presence of } 50 \mu \mathrm{M} \text { amiloride or } 50^{\prime} \text {; saliva and was corrected for the } 7.0^{\prime \prime} \\
\text { inhibition observed with artificial saliva (lig. 2). Specitic inhibition of the } \\
\text { short-circuit current was calculated as described in the text (see "Results"). } \\
\text { "Mean } \pm \text { S.E. } \\
\text { "Numbers in parentheses, number of animals (amiloride) or individuals }\end{array}$} \\
\hline
\end{tabular}

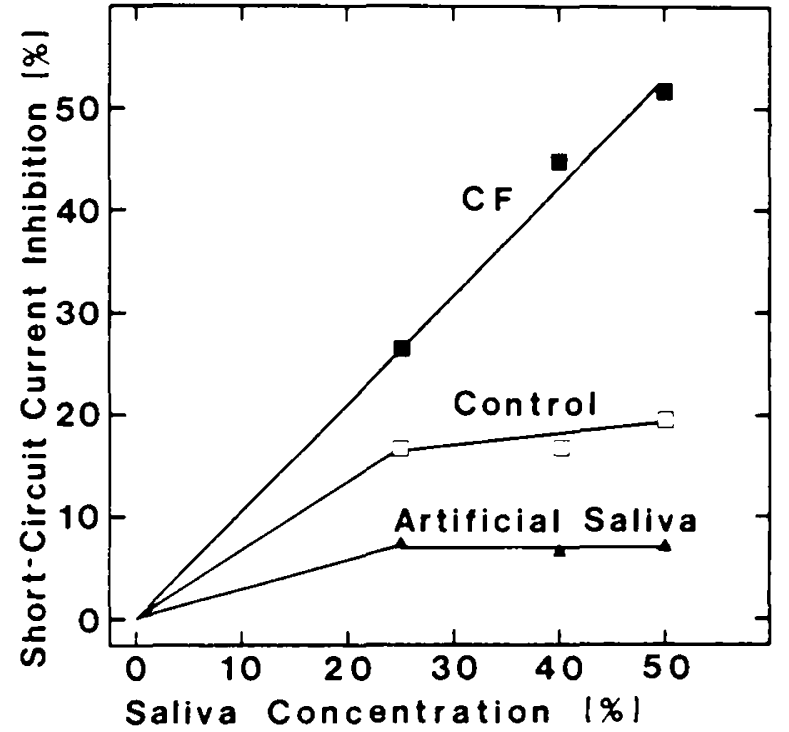

Fig. 3. Concentration dependence of the inhibition of the colonic shortcircuit current by $\mathrm{C} F$ and control saliva. Saliva was obtained from a normal 30-yr-old male $(\square)$ and a 28 -yr-old CF patient $(\square)$ with a clinical score of 74 . Artificial saliva $(\Delta)$ was used to mimic the effect of just the electrolytes in saliva. Samples were assayed for inhibitory activity using the same piece of tissue. Saliva concentrations above $50^{\circ}$ " cannot be tested because of foaming in the chamber.

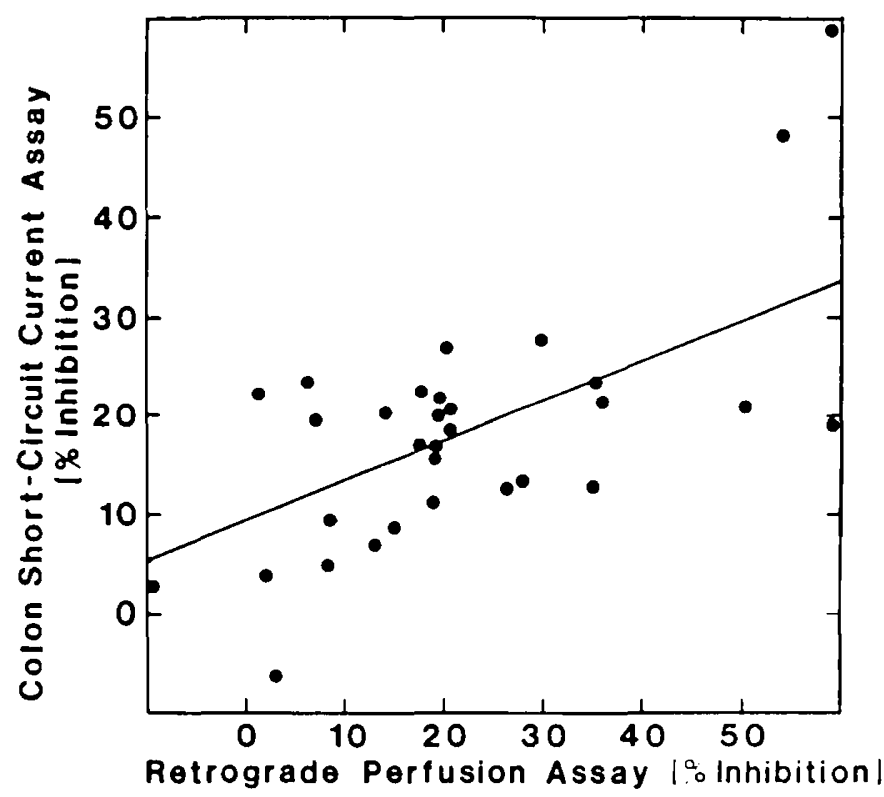

Fig. 4. Correlation between the saliva activity inhibiting the shortcircuit current of the rat colon and the activity inhibiting the reabsorption of sodium by the rat parotid gland. The ductal retrograde perfusion assay of the rat parotid was performed according to Taylor et al. (38). Inhibition of the colonic short-circuit current by $25 \%$; saliva was measured as described in "Materials and Methods." The linear correlation between the activities measured by the two assays in 31 trials may be described by $y$ $=0.404 \times+9.54$ with a correlation coefficient of $0.634, P<0.005$.

expected from the results in Figure 2 that large volumes of saliva would decrease the short-circuit current by reducing the sodium concentration at the mucosal surface. The inhibition observed with saliva is not due to such as effect because of the following observations: (1) the "inhibition" due to a reduced electrolyte concentration ( $50 \%$ saliva would produce a luminal sodium concentration of $\sim 80 \mathrm{mM}$ ) would be only $\sim 7 \%$ (estimated from Fig. 
Table 2. Sodium and potassium concentrations in control and $C F$ salivas $^{1}$

\begin{tabular}{lcc} 
& \multicolumn{2}{c}{ Concentration $(\mathrm{mM})$} \\
\multicolumn{1}{c}{ Saliva } & Sodium & Potassium \\
\hline Control & $12.8 \pm 1.2^{2}(17)^{\prime}$ & $16.1 \pm 6.1(10)$ \\
CF & $20.7 \pm 2.5 \quad(17)$ & $19.8 \pm 5.8(12)$ \\
Significance $t$ test & $P<0.01$ & $P>0.10$ \\
\hline
\end{tabular}

${ }^{1}$ Sodium and potassium concentrations of mixed sublingual-submaxillary salivas were measured with a flame photometer using lithium chloride as an internal standard (40).

Mean \pm S.E.

${ }^{t}$ Numbers in parentheses, number of individuals.

Table 3. Effect of electrolyte adjustment on the inhibition of colonic short-circuit current by specific CF and control salivas'

$$
" \text { inhibition observed with } 25 \%
$$
saliva

\begin{tabular}{lclcc}
\multicolumn{1}{c}{ Individual } & Age & Sex & $\begin{array}{c}\text { Before } \\
\text { adjustment }\end{array}$ & $\begin{array}{c}\text { After } \\
\text { adjustment }\end{array}$ \\
CF-1 & 25 & Female & 14 & 14 \\
CF-2 & 24 & Male & 29 & 23 \\
CF-3 & 17 & Male & 20 & 17 \\
Control-1 & 33 & Female & 14 & 11 \\
Control-2 & 25 & Male & 19 & 11 \\
Control-3 & 30 & Male & 10 & 10
\end{tabular}

'Inhibition of short-circuit current by specific saliva samples was measured as described in "Material: d Methods." Inhibition was measured before and after adjustment of electrolytes to equal those in KrebsHenseleit buffer

2) which is comparable to that observed with artificial saliva (Fig. $3)$, however. this is very much less than that actually observed with saliva (Fig. 3: Table 1): (2) the difference between the sodium concentrations in CF and control saliva, although significant (Table 2; see Refs. 8 and 41 ) is relatively small. Because the sodium concentration in control saliva is less than that of $\mathrm{CF}$ saliva, from the results in Figure 2, one would expect more inhibition from the control saliva. The opposite is actually observed (Table 1): ( 3 ) when the inhibition by specific saliva samples was measured before and after adjustment of the electrolytes to equal that of Krebs-Henseleit solution (Table 3 ), the inhibition persisted after the electrolytes had been adjusted. Therefore, the inhibition cannot be due to an electrolyte imbalance; and (4) when CF saliva was treated with Dowex chelating resin or Norit $A$ (activated charcoal), the inhibition was reduced from 14 to $6 \%$ without a significant change in the electrolyte concentrations (results not shown). These observations strongly support the hypothesis that an inhibitor of sodium transport is present in saliva and is elevated in saliva from $C F$ patients.

The increased inhibition in the CF saliva, as compared to the saliva from controls (Table 1 ), is probably not due to direct effects of medication being secreted in the saliva because the following compounds at $10 \mu \mathrm{M}$ had no effect on the short-circuit current: atropine, $l$-epinephrine, gentamicin, guanosine $3^{\prime}: 5^{\prime}$ cyclic monophosphate, $l$-isoproterenol, methacholine, $l$-norepinephrine, $\mathrm{N}^{6}, \mathrm{O}^{2 \prime}$-dibutyryl adenosine $3^{\prime}: 5^{\prime}$ cyclic monophosphate, $l$-propranolol, penicillin, trimethoprim, and tetracycline. These represent the majority of pharmacologic agents administered to CF patients on a chronic basis (41) and argue against any CF-control difference being drug related.

\section{DISCUSSION}

Our results confirm those of earlier studies $(24,27,28,38)$ with regard to a specific inhibition of sodium reabsorption by amilor- ide-sensitive sodium scavenging epithelia $(19,29,32)$. Our study. like earlier studies $(24,27,28,38)$ has been performed with $C F$ saliva run in parallel with sex- and age-matched normal controls. However, to be more certain of the CF specificity of the inhibitory activity, it will be necessary to extend our studies using age- and sex-matched controls who have other appropriate chronic lung diseases. Such controls were not included in the current study because of practical problems in obtaining the appropriate diseased controls and because we observed that the specific inhibition actually decreases with an increase in the severity of CF (linear correlation coefficient of specific inhibition with total clinical score $=0.406$ (with 15 patients and a total of 23 measurements of inhibitory activity) $(P<0.05)$.

Comparison of the absolute inhibition of the short-circuit current indicates that CF saliva is, on the average, $37 \%$ more potent than is control saliva in its ability to inhibit sodium transport (Table 1). The magnitude of the CF effect does not appear very large. However, it is reasonable when one considers that the ability of salivary ducts to reabsorb sodium is only slightly impaired in CF patients, as judged for example. by the sodium concentration in the secreted saliva (Table 2; see Refs. 8 and 41 ).

The results described above are consistent with our hypothesis that CF factors probably inhibit sodium transport by low conductance epithelia in a manner similar to that of amiloride (23. 32.39 ). The short-circuit current of the colon from sodium-deficient rats is completely inhibited by low concentrations of amiloride (apparent $\mathrm{K}_{1} \simeq 0.5 \mu \mathrm{M}$ ) like other epithelia which are sensitive to $\mathrm{CF}$ sodium transport inhibitory activity $(32,34)$. The reversibility of the inhibition of the short-circuit current after both amiloride and CF saliva indicates that neither is affecting the viability of the tissue: this property and the fact that the colonic epithelium remains sensitive to amiloride for 3 to $6 \mathrm{hr}$ in vitro are advantageous for assay purposes as multiple samples can be rapidly assayed using a single piece of tissue.

The use of the inhibition of the short-circuit current of the colon as an assay for CF factor activity will greatly facilitate the characterization, isolation, and identification of the CF factor(s). Such an effort is presently underway in our laboratories (9). It is hoped that isolation of the CF sodium transport-inhibitory activity will contribute to determining the underlying biochemical error which is present in CF exocrine tissues.

\section{CONCLUSION}

CF saliva reversibly inhibits epithelial sodium transport that probably proceeds via the amiloride-sensitive transport system. Sodium absorption by an amiloride-insensitive transport system is not inhibited. CF saliva is significantly more inhibitory than control saliva and the inhibitory activity measured with the rat colon correlates with the inhibition measured by the rat parotid retrograde perfusion assay.

\section{REFEREN(ES ANI) NOTES}

1. Araki. H., Field, M., and Shwachman. H.: A new assay for cystic tibrosis factor effects of sera from patients with cystic tibross in the in vitro electrical properties of rat jejunum. Pediatr. Res. $4: 932$ (1975).

2. Araki. H.. Field. M., and Shwachman. H.: A new assay for cystic tibrosis factor: effect of sera from patients with cystic tibrosis on the in vitro electrical properties of rat jejunum. In: Seventh International Cystic Fibrosis Congress Proceedings. Paris, France. p. 120 (1976).

3. Benke, P. J., Erbstoeszer, M., and Pitot, H. C.: Transport of labelled compounds in control and cystic-fibrosis cells in vitro. Lancet. $l$ : 182 (1972).

4. Burg. M. B.: Tubular chloride transport and the mode of action of some diuretics Kidney Int.. 9: 189 $\{1976\}$.

5. Brown. G. A., Oshin. A. Cioodchild. M. C... and Anderson. C. M.: Inhibition of sugar transport by plasma from cystic fibrosis patients. Lancet. 2: 639) (1971)

6. Cousin. J. L.. and Motais. R.: The role of carbonic anhydrase inhibitors on anion permeability into ox red hlood cells. J. Physiol. (lond.). 25n: 61 (1976).

7. Daniel. W. W.: Bostatistics: A Foundation for Analysis in the Health Sciences. pp. 163-166, 253-254 (John Wiley \& Sons Inc.. New York. 1974)

8. Dearborn, D. G.: Water and electrolytes of exocrine secretions. In: J. A. Mangos, R. C. Talamo: Cystic Fibrosis, Projections into the Future. pp. 179-191 (Symposia Specialists. Miami, FL, 1976).

9. Dearborn. D. (i.. Will. P. C.. Cierken. T. A.. and Hopler. U.: Partial puritication of an inhibitor of sodium transport from cystic lihrosis saliva. In: Eighth 
International congress on Cystic Fibrosis Proceedings. Toronto. Canada. $p$ 11 a $(1980)$

10. di Sant Agnese. P. A.. and Davis. P. B.: Research in cystic tihrosis. N. Engl. J Med.. 2y.5: 481. 534, 597 (1976)

I1. di Sant Agnese. P. A.. and Talamo. R. ( 2 . Pathogenesis and physiopathology of cystic tihrosis of the pancreas. N. Fngl. J. Med.. 277: 1287. 1344. 1394 (1967).

12. Doershuk. ('. F.. Matthews. I. W.. Tucker. A. S.. Nudelman. H.. Fddy. (i.. Wise. M.. and Spector. S.: A 5 vear clinical evalution of a therapeutic program for patients with cystic fibrosis. J. Pediatr.. 05: $677(1964)$

13. Edmonds. ( . J.: The gradient of electrical potential ditference and of sodium and potassium of the gut contents along the caecum and colon of normal and sodium-depleted rats. J. Physiol. (1.ond.). 113:5: 571 (1967)

14. Edmonds. ('. J.. and Marrioti. J.: Sodium transport and short-circuit current in rat colon in vivo and the effect of aldosterone. J. Physiol. (l.ond.). 210: 1021 (1970).

15. Edmonds, C. J., and Pilcher, D.: Sodium transport mechanisms of the large intestine. In: W. L. Burland. P. P. Samuel: Transport Across the Intestine. pp. 43-57. (Churchill Livingstone. Edinburg. 1972).

16. Erlij. D.: Solute transport across isolated epithelia. Kidney Int., 9: 76 (1976).

17. Frizell. R. A.. Koch. M. J.. and Schultz. S. (i.: Ion transport by rabhit colon. I Active and passive components. J. Membr. Biol.. 2-: 297 (1976)

18. Frizell. R. A.. and Turnheim. K.: Ion Transport hy rahbit colon. II. Unidirectional sodium influx and the effects of amphotericin $B$ and amiloride. J. Membr. Biol.. 41): 193 (1978)

19. Fromter. E.. and Diamond. J.: Route of passive ion permeation in epithelia. Nat. New Biol. 235: 9 (1972).

20. Gibson. L. E.. di Sant Agnese. P. A.. and Shwachman. H.: Procedure for the quantitative iontophoretic sweat test. Cvstic Fihrosis Foundation Publication MED-P-49. Atlanta. ( $A$ A (1975)

21. Giruber. W. D.. Knauf. H.. and Fromter. F.. The action of aldosterone on $\mathrm{Na}^{\prime}$ and $\mathrm{K}^{\prime}$ transport in the rat submaxillary main duct. Pfluger's Arch. Eur. J Physiol.. 344: 33 (1973).

22. Hartroft. P. M. and Eisenstein. A. B. Alterations in the adrenal cortex of the rat induced by sodium deficiency: (orrelation of histologic changes with steroid hormone secretion. Endocrinology, of): 641 (1957).

23. Hopfer. U.. Will. P. (... and Dearborn. D). (;.) (ystic tibrosis: A secondary endocrine or target tissue sensitivity problem in epithelial electrolyte transport? Fighth International ('ongress on ( ystic Fihrosis Proceedings. Toronto, Canada. p. 2()a (1980).

24. Kaiser. D.. Drack. E.. and Rossi. E.: Effect of cystic fibrosis sweat on sodium reabsorption by the normal sweat gland. Lancet. I: 1003 (1970)

25. Knauf. P. A... and Rothstein. A.: ('hemical modification of membranes. I. Effects of sulthydryl and amino reactive reagents on anion and cation permeability of the human red hlood cell. J. (ien. Physiol.. s.: 190) (1971).

26. Long. (C. (ed.): Biochemists Handbook. p. 58 (D. Van Nostrand (o. Inc. Princeton. NJ $|96|)$.

27. Mangos. J. A.. and McSherrv. N. R.: Sodium transport: inhibitory factor in sweat of patients with cystic fibrosis. Science (Wash. D). (.). 15.8: 135 (1967).

28. Mangos. J. A.. McSherry. N. R.. and Benke. P. J.: A sodium transport inhibitory factor in the saliva of patients with cystic fihrosis of the pancreas. Pediatr Res.. 1: 436 (1967).

29. Meng. K.: Comparison of the local effects of amiloride hydrochloride on the isotonic tluid aborption in the distal and proximal convoluted tubule. Plluger: Arch. Eur. J. Physiol.. 357: 9 ! (1975)

30. Morin. C. L.. Desjeux. J. F.. and Authier. 1... Effect of saliva and serum from patients with cystic fibrosis on intestinal uptake of amino acids in rat. Biomed. Express (Paris). 14: 133 (1973)

31. Nellans, H. N.. and Schult, S. (i.: Relations among transepithelial sodium transport. potassium exchange, and cell volume in rahbit tleum. J. (ien. Physiol.. 6.8: 441 (1976)

32. Quinton. P. M.: An induced model of cystic tibrosis in normal sweat glands Eighteenth (ystic Fibrosis (Club Meeting. San Francisco, ( A. 1977. Abstract in: Cystic Fibrosis Quarterly Annotated References, 15: 51 (1976).

33. Schnever. L. H.: (ollection of separate submaxillary and sublingual salivas in man. J. Dent. Res.. 33: 683 (1954).

34. Schnever. L. H.: Amiloride inhibition of ion transport in perfused excretory duct of rat submaxillary gland. Am. J. Physiol.. 2/9:1050 (1970).

35. Schneyer. L. H. Young. J. A.. and Schnever. ('. A.: Salivary secretion of electrolytes. Physiol. Rev.. 52: 720 (1972)

36. Shwachman, H., and Kulczycki, L. L.: Long-term study of one hundred five patients with cystic fibrosis. Am. J. Dis. Child., 96: 6 (1958).

37. Taussig, L. M.. and Gardner, J. D.: Effects of saliva and plasma from cystic fibrosis patients on membrane transport. Lancet. $I: 1367$ (1972).

38. Taylor. A.. Mayo, J. W. Boat. T. F. and Matthews, L. W. Standardized assay for the sodium reabsorption inhibitory effect and studies of its salivary gland distribution in patients with cystic tibrosis. Pediatr. Res.. s: 861 (1974).

39. Will, P. (., Boat. T. F.. and Hopfer. U.: Evidence against a specific effect of serum from patients with cystic fibrosis on sodium-dependent glucose transport in the rat jejunum. Pediatr. Res.. 13: $1129(1979)$.

40. Willard. H. H.. Merritt. L. L.., and Dean. J. A.: Instrumental methods of analysis. F.d. 4. p. 309356 (D. Van Nostrand (i). Inc.. Princeton. NJ. 1965)

41. Wood. R. E.. Boat. T. F.. and Doershuk. ( . F.: State of the art: cystic librosis Am. Rev. Respir. Dis.. 113:833 (1976).

42. Zadunaisky. J. A.: Active transport of chloride in frog cornea. Am. J. Physiol.. ?11: $506(1966)$.

43. A preliminary report of this work was published as an abstract of the Nineteenth Cystic Fibrosis Club Meeting. April 25. 1978. New York. NY: In: Cystic Fibrosis Quarterly Annotated References 1.5: 56 (1978).

44. The authors thank Mr. John I). Compson, and Mr. Ronald $\mathrm{N}$. (ortright for technical assistance. and Dr. Robert Stern for help with the clinical scores.

45. Requests for reprints should be addressed to: Dr. Ulrich Hopfer. Department of Anatomy, (ase Western Reserve University. ( leveland. OH 44I()6 (USA).

46. This research was supported by grant number AM-0)305 from the United States Public Health Service. Basil O ( onnor grant number 5-126 from the Nationa Foundation. March of Dimes, and contract number HR 7-2920 from the United States Public Health Service.

47. Received for publication July 2. 1979.

48. Accepted for publication February 5. 1980. 